This is an open-access article distributed under the terms of the Creative Commons Attribution License, which permits unrestricted use, distribution, and reproduction in any medium, provided the original author and source are credited.

Am. J. Trop. Med. Hyg., 00(00), 2021, pp. 1-5

doi:10.4269/ajtmh.20-1129

Copyright $(2021$ by The American Society of Tropical Medicine and Hygiene

\title{
Perspective Piece \\ A One Health Approach to Child Stunting: Evidence and Research Agenda
}

\author{
Radhika Gharpure, ${ }^{1 \star}$ Siobhan M. Mor, ${ }^{2,3}$ Mark Viney, ${ }^{4}$ Tinashe Hodobo, ${ }^{5}$ Joanne Lello, ${ }^{6}$ Joyce Siwila, ${ }^{7}$ Kululeko Dube, ${ }^{8}$ \\ Ruairi C. Robertson, ${ }^{9}$ Kuda Mutasa, ${ }^{10}$ Cedric N. Berger, ${ }^{6}$ Mitsuaki Hirai, ${ }^{11}$ Tim Brown, ${ }^{12}$ Robert Ntozini, ${ }^{10}$ \\ Ceri Evans, ${ }^{9,10}$ Patience Hoto, ${ }^{8}$ Laura E. Smith, ${ }^{10,13}$ Naume V. Tavengwa, ${ }^{10}$ Mathieu Joyeux, ${ }^{11}$ Jean H. Humphrey, ${ }^{10,14}$
} David Berendes, ${ }^{1}$ and Andrew J. Prendergast ${ }^{9,10,14}$

\begin{abstract}
${ }^{1}$ Division of Foodborne, Waterborne, and Environmental Diseases, National Center for Emerging and Zoonotic Infectious Diseases, Centers for Disease Control and Prevention, Atlanta, Georgia; ${ }^{2}$ Institute of Infection, Veterinary and Ecological Sciences, University of Liverpool, Liverpool, United Kingdom; ${ }^{3}$ International Livestock Research Institute, Addis Ababa, Ethiopia; ${ }^{4}$ Department of Evolution, Ecology and Behaviour, Institute of Infection, Veterinary and Ecological Sciences, University of Liverpool, Liverpool, United Kingdom; ${ }^{5}$ Central Veterinary Laboratory, Harare, Zimbabwe; ${ }^{6}$ College of Biomedical and Life Sciences, Cardiff University, Cardiff, United Kingdom; ${ }^{7}$ School of Veterinary Medicine, University of Zambia, Lusaka, Zambia; ${ }^{8}$ Food and Agriculture Organization of the United Nations, Harare, Zimbabwe; ${ }^{9}$ Blizard Institute, Queen Mary University of London, London, United Kingdom; ${ }^{10}$ Zvitambo Institute for Maternal and Child Health Research, Harare, Zimbabwe; ${ }^{11}$ United Nations Children's Fund, Harare, Zimbabwe; ${ }^{12}$ School of Geography, Queen Mary University of London, London, United Kingdom; ${ }^{13}$ Department of Epidemiology and Environmental Health, University at Buffalo, Buffalo, New York; ${ }^{14}$ Department of International Health, Johns Hopkins Bloomberg School
\end{abstract} of Public Health, Baltimore, Maryland

Abstract. Stunting (low height for age) affects approximately one-quarter of children aged $<5$ years worldwide. Given the limited impact of current interventions for stunting, new multisectoral evidence-based approaches are needed to decrease the burden of stunting in low- and middle-income countries (LMICs). Recognizing that the health of people, animals, and the environment are connected, we present the rationale and research agenda for considering a One Health approach to child stunting. We contend that a One Health strategy may uncover new approaches to tackling child stunting by addressing several interdependent factors that prevent children from thriving in LMICs, and that coordinated interventions among human health, animal health, and environmental health sectors may have a synergistic effect in stunting reduction.

Stunting (low height for age) affects approximately onequarter of children aged $<5$ years ${ }^{1}$ and is associated with increased mortality, impaired neurodevelopment, elevated chronic disease risk, and reduced productivity. ${ }^{2}$ Despite gradual global declines in stunting prevalence, the absolute number of stunted children in Africa is increasing because of population growth. ${ }^{1}$ Nutrition interventions would reduce stunting prevalence by only $20 \%$ if implemented with $90 \%$ global coverage ${ }^{3}$; thus, additional approaches to complement nutrition interventions are needed. ${ }^{4}$

Preventing diarrhea through improved water, sanitation, and hygiene $(\mathrm{WaSH})$ is central to stunting reduction efforts. ${ }^{5}$ However, recent studies using molecular methods to identify fecal pathogens have shown that enteropathogen colonization in low- and middle-income countries (LMICs) occurs much earlier in life than previously realized, and subclinical carriage is associated with larger and more sustained decrements in linear growth than diarrhea. ${ }^{6,7}$ It is hypothesized that infection by fecal microbes drives environmental enteric dysfunction (EED), a subclinical disorder of the small intestine characterized by inflammation, permeability, and malabsorption, and that EED contributes to stunting. ${ }^{8}$ However, randomized controlled trials of household-level WaSH interventions to interrupt fecal-oral transmission pathways in infants have failed to improve linear growth, ${ }^{9}$ and transformative approaches are therefore required. ${ }^{10}$

Recently, we argued that reducing microbial transmission from animals to children is an overlooked component of most

\footnotetext{
*Address correspondence to Radhika Gharpure, Division of Foodborne, Waterborne, and Environmental Diseases, National Center for Emerging and Zoonotic Infectious Diseases, Centers for Disease Control and Prevention, 600 Clifton Rd. NE, Mailstop H24-10, Atlanta, GA 30329. E-mail: rgharpure@cdc.gov
}

WaSH programs because animal feces may be a major source of enteropathogens. ${ }^{11}$ However, strategies to separate animals and their feces from children must also consider the importance of animals for rural livelihoods, as well as the health of their shared environments. A holistic approach, considering human, animal, and environmental health as One Health, may be central to successfully reducing stunting.

\section{EVIDENCE FOR A ONE HEALTH APPROACH}

Animal-human links. Livestock contribute to the livelihoods of $70 \%$ of the world's rural poor. ${ }^{12}$ An estimated $85 \%$ of rural households in sub-Saharan Africa keep poultry, ${ }^{13}$ with similar estimates for Asia ${ }^{14,15}$ and Latin America. ${ }^{16}$ Poultry and other peri-domestic livestock, including cattle, goats, sheep, and pigs, are economic assets; have sociocultural value; and provide labor, transportation, fertilizer, and fuel. ${ }^{17}$ Animalsource foods, such as milk, eggs, and meat, can prevent or ameliorate micronutrient deficiencies and provide high-quality protein. ${ }^{18}$ However, livestock and other peri-domestic animals (e.g., dogs and cats) are a source of fecal contamination of the domestic environment. Shared pathogenic and nonpathogenic microbes have been identified in humans and animals living in close proximity, ${ }^{19,20}$ and animal fecal pathogens can cause diarrhea ${ }^{21}$ and other adverse health outcomes $^{22}$ in humans.

Animal-environmental links. With nearly 30 billion livestock animals on earth, recent estimates indicate 4-fold higher global production of animal feces compared with human feces. ${ }^{23}$ Management of animal feces is highly unregulated in LMICs and neglected in most WaSH programs. ${ }^{11}$ This particularly affects populations in rural LMICs who own peridomestic animals, which typically forage freely within the household compound and are often kept indoors at night for 
security. Without adequate sanitation and hygiene, household environments and drinking water sources can become contaminated with animal feces, ${ }^{24-26}$ and multiple studies from Bangladesh and India have used microbial source-tracking to identify animal fecal-derived contamination in household environments and on human hands. ${ }^{27-29}$

Environmental-human links. Exposure to human fecal pathogens due to unsafe or insufficient $\mathrm{WaSH}$ resources causes a significant burden of diarrheal disease in LMICs. ${ }^{30}$ Fecal contamination of the environment from human sanitation systems, including inadequate household sanitation systems and low community-level coverage, is well-documented $^{31}$ and may be compounded by fecal contamination from animal sources. Conventional sanitation improvements focused on isolating human feces have failed to reduce fecal contamination in the environment ${ }^{32}$; this may be in part because animal feces are not adequately managed.

On an individual scale, infants interact with their environments through hand- and object-mouthing, a common exploratory behavior during early development stages. ${ }^{33}$ Research from Bangladesh suggests that hand- and objectmouthing is more common in rural LMICs than in high-income countries. ${ }^{34}$ Geophagia, or ingestion of soil, is hypothesized to be an important route of fecal-oral transmission in infants, potentially contributing to enteropathogen carriage, diarrhea, EED, and, in turn, stunting. ${ }^{35}$ Studies from Bangladesh confirmed that children with reported geophagia have higher markers of EED ${ }^{36,37}$ and increased odds of stunting. ${ }^{36,38}$

Pulling it together: Human-animal-environmental links to stunting. Several studies have highlighted that the interactions between humans, animals, and their shared environment may impact childhood growth. Environmental contamination with animal feces has been linked to child stunting in observational datasets: a study in Bangladesh and Ethiopia identified a negative association between the presence of animal feces in the compound and child heightfor-age Z-scores. ${ }^{39}$ In Ethiopia, poultry ownership reduced the risk of stunting through increased consumption of eggs; however, corralling poultry in the household overnight increased the risk of stunting, suggesting that proximity of children and animals may be an important consideration. ${ }^{40}$ Among Bangladeshi households owning poultry, an animal corral in a child's sleeping room was associated with elevated EED biomarkers and increased odds of stunting ${ }^{37}$; similarly, in Malawi, having an animal in a child's sleeping environment was associated with EED. ${ }^{41}$ During an observational study in rural Zimbabwe to identify potential pathways of fecal-oral transmission that may contribute to stunting, $87 \%$ of household yards contained chicken feces, and infants actively ingested soil and dried chicken feces. ${ }^{35}$ Collectively, existing knowledge regarding human-animal-environmental linkages provides a strong rationale for a One Health approach to child stunting (Figure 1).

\section{UNKNOWNS AND RESEARCH AGENDA}

A multisectoral approach has the potential to improve human, animal, and environmental health in tandem and could inform the design of appropriate interventions to alleviate child undernutrition, reduce environmental fecal exposure, and maximize animal health, production, and welfare. To address current knowledge gaps, we propose a research agenda (Figure 2) with three goals outlined in the following paragraphs.

Define the relationship between microbial carriage and child health. Microbial carriage and shedding in animals may be influenced by age, health status, diet, management, ${ }^{42}$ and spatiotemporal dynamics ${ }^{43}$; to our knowledge, these factors have not been well-evaluated in rural LMIC settings. Furthermore, characteristics of the environment itself (e.g., soil characteristics) may impact microbial diversity. ${ }^{44,45}$ The magnitude
1. Animals are commonly kept in household environments in rural LMIC with minimal housing/confinement.

2. Animal feces can contaminate household floors, soil, and water sources. ${ }^{24,25,26}$

3. Animals can acquire microorganisms from their environment. ${ }^{19}$
1. Environments can become contaminated with human feces in the absence of adequate WaSH infrastructure. ${ }^{30,} 31$

2. Young children explore their environment through geophagia (ingestion of soil). ${ }^{33}$

3. Geophagia has been linked with environmental enteric dysfunction and stunting. ${ }^{35,36,37,38}$

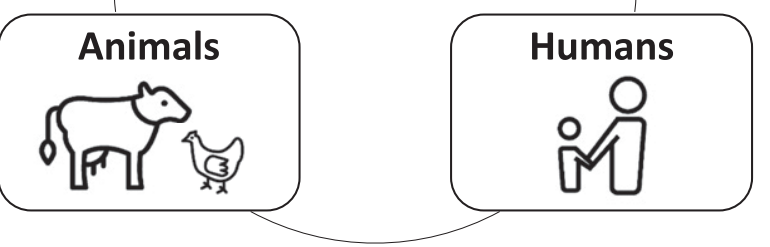

1. Animals provide nutritional, economic, and other benefits to rural households. ${ }^{17,18}$

2. Microbes can shared between humans and animals. ${ }^{19,} 20$

3. Pathogens from animal sources can cause diarrhea and other adverse health outcomes in humans. ${ }^{21,22}$

FigURE 1. Evidence to support the need for a One Health approach to stunting 


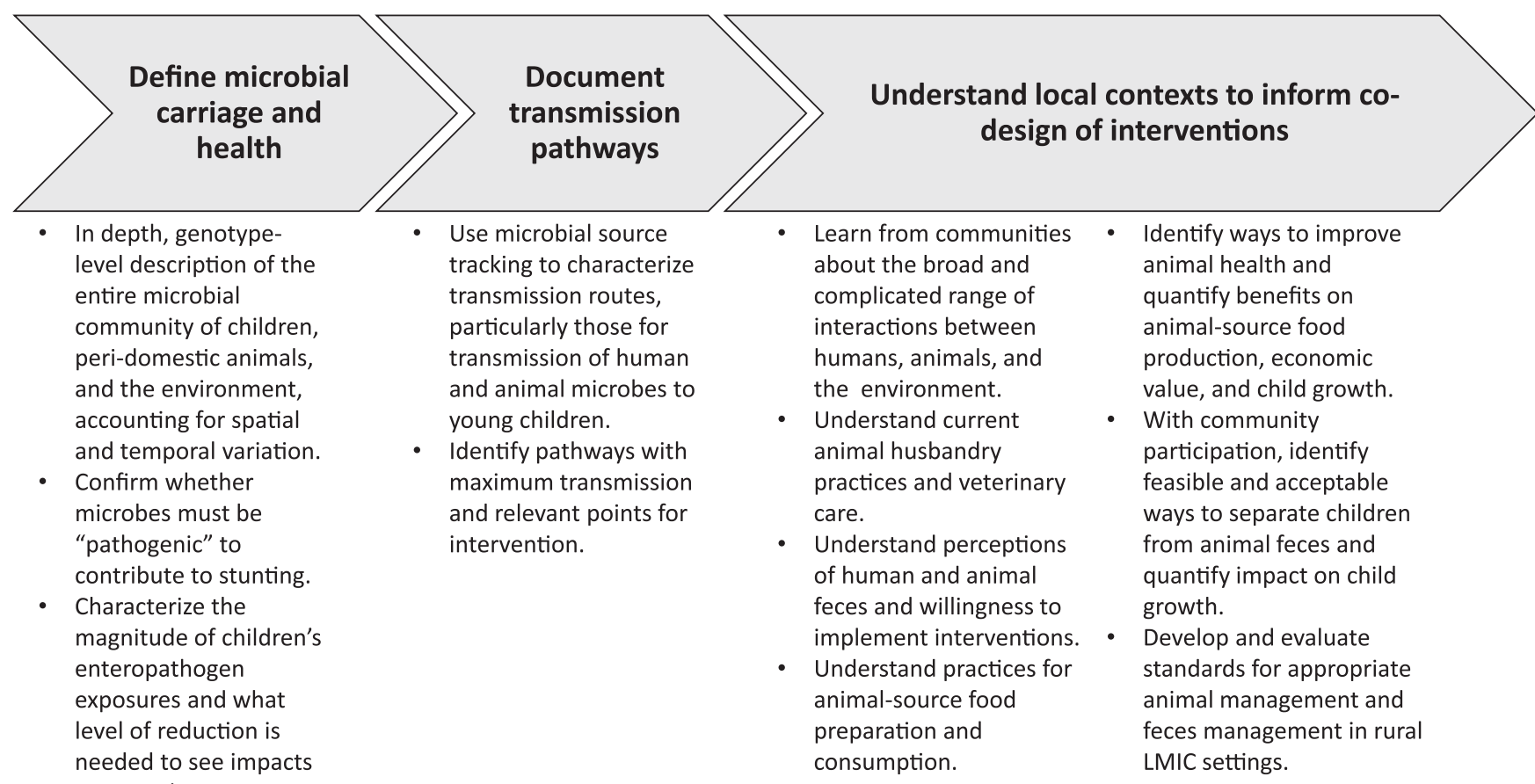

FIGURE 2. Proposed research agenda to fill knowledge gaps for a One Health approach to stunting. LMICs $=$ low- and middle-income countries.

and spectrum of human carriage of animal-derived microbes is poorly characterized, ${ }^{46}$ and the risk to human health from animal feces has not been systematically quantified. ${ }^{46}$ It is unclear whether microbes from human and animal feces must be traditionally "pathogenic" to contribute to EED. Certain microbes can be conditionally pathogenic (so-called "pathobionts") in both humans and animals depending on health status and other environmental factors. ${ }^{47}$ Evidence regarding whether some animals contribute more than others to child enteropathogen carriage (because of species compatibility, magnitude of shedding, or frequency of contact) remains limited, ${ }^{48}$ and it is uncertain how much reduction in fecal microbe ingestion is required for child health gains. Genotypelevel microbiome evaluations of children, peri-domestic animals, and the environment, accounting for spatiotemporal variation, would improve our understanding of shared microbial communities. Next-generation sequencing and other stool-based molecular techniques may assist in characterizing shared species and strains. ${ }^{49,50}$

Document transmission pathways. Proposed routes for transmission of fecal pathogens from animals to humans include the "modified F-diagram" factors: fluids (water sources), fields (or soil), food, flies, fingers, and fomites (objects and surfaces), which are routes of transmission shared with human feces. ${ }^{22}$ However, further research is needed to quantify the risk from each pathway, identify novel transmission routes (particularly in young, pre-mobile infants during breastfeeding), and ascertain key points for intervention in different contexts. $A$ broader One Health approach should strive to characterize and quantify microbial transmission routes not just to humans but also among different animal species and the environment, as well as the consequences for animal health and production. Furthermore, environmental contamination from release of untreated human and animal fecal waste into the environment may perpetuate cycles of reinfection through repeated exposure and shedding and may contribute to emergence of antimicrobial resistance ${ }^{51}$; transmission of resistant organisms and consequences for human, animal, and environmental health should be further characterized.

Understand local contexts to inform interventions. There is need to learn about the range of interactions between humans, animals, and the environment from communities to identify ways of promoting the benefits of livestock ownership while minimizing the risks of fecal microbe exposure. Intervention trials to reduce microbial transmission from peridomestic animals are a critical proof-of-concept step. Among the few trials specifically aimed at reducing peri-domestic animal fecal contamination, ${ }^{52}$ interventions have included separating animals (specifically poultry) from human living spaces, creating safe play spaces for children, providing animal feces scoops, and improving veterinary care. ${ }^{22}$ The first three strategies have had limited effectiveness in reducing animal fecal contamination, ${ }^{22}$ and uptake of corralling interventions may be poor because of $\operatorname{cost}^{53}$ and community perception. ${ }^{54}$

Formative work regarding animal husbandry practices and perceptions of animal feces was included in the CAGED trial in Ethiopia ${ }^{55}$ and the SELEVER trial in Burkina Faso, ${ }^{56}$ and similar context-specific results may inform new interventions in additional settings. Agricultural extension interventions may be explored to improve delivery of animal health services and increase production of animal-source foods, ${ }^{57}$ although more research is needed to characterize the impact of these foods on child growth ${ }^{58}$ and to develop economically sustainable livestock production models. ${ }^{59}$ Consideration of animal feces in the design of $\mathrm{WaSH}$ interventions may also have potential to reduce pathogen burden and promote child health. ${ }^{11} \mathrm{Co}-$ design of One Health strategies through community participation, considering the feasibility, acceptability, and trade-offs of different models, may be the most effective approach for each unique setting and context. 
In summary, we believe our proposed research agenda could uncover new approaches to reducing child stunting by tackling several interdependent factors that prevent children from thriving in LMICs. A One Health approach could yield collective benefits by concurrently promoting the health of people, animals, and environments.

Received September 2, 2020. Accepted for publication October 19, 2020.

Published online March 8, 2021.

Acknowledgments: We thank Shamiso Fernando, Virginia Sauramba, Philipa Rambanepasi, Dzivaidzo Chidhanguro, Batsirai Mutasa, Bernard Chasekwa, Florence Majo, Lisa Hurt, and Susan Craddock for their contributions to the meeting that led to this manuscript in Harare, Zimbabwe, on May 22-23, 2019.

Financial support: The May 2019 meeting was funded by the U.K. Medical Research Council (grant MC_PC_MR/R019436/1). A. J. P., R. C. R., and C. E. received funds from the Wellcome Trust (grants 108065/Z/15/Z, 206455/Z/17/Z, and 203905/Z/16/Z).

Disclaimer: The findings and conclusions in this report are those of the authors and do not necessarily represent the official position of their institutions.

Authors' addresses: Radhika Gharpure and David Berendes, Division of Foodborne, Waterborne, and Environmental Diseases, National Center for Emerging and Zoonotic Infectious Diseases, Centers for Disease Control and Prevention, Atlanta, GA, E-mails: krr4@cdc.gov and uws8@cdc.gov. Siobhan Mor, Institute of Infection, Veterinary and Ecological Sciences, University of Liverpool, Liverpool, United Kingdom, E-mail: siobhan.mor@liverpool.ac.uk. Mark Viney, Institute of Infection, Veterinary and Ecological Sciences, University of Liverpool, Liverpool, United Kingdom, E-mail: mark.viney@liverpool.ac.uk. Tinashe Hodobo, Central Veterinary Laboratory, Harare, Zimbabwe, E-mail: tinashehdb@gmail.com. Joanne Lello and Cedric Berger, College of Biomedical and Life Sciences, Cardiff University, Cardiff, United Kingdom, E-mails: lelloj@cardiff.ac.uk and bergerc3@ cardiff.ac.uk. Joyce Siwila, School of Veterinary Medicine, University of Zambia, Lusaka, Zambia, E-mail: siwilaj@yahoo.co.uk. Kululeko Dube and Patience Hoto, Food and Agriculture Organization of the United Nations, Harare, Zimbabwe, E-mails: kululeko.dube@fao.org and patience.hoto@fao.org. Ruairi C. Robertson, Ceri Evans, and Andrew J. Prendergast, Blizard Institute, Queen Mary University of London, London, United Kingdom, E-mails: r.robertson@qmul.ac.uk, ceri.evans@qmul.ac.uk, and a.prendergast@qmul.ac.uk. Mitsuaki Hirai and Mathieu Joyeux, UNICEF, Harare, Zimbabwe, E-mails: mhirai@ unicef.org and mjoyeux@unicef.org. Tim Brown, School of Geography, Queen Mary University of London, London, United Kingdom, E-mail: tim.brown@qmul.ac.uk. Kuda Mutasa, Robert Ntozini, Laura E. Smith, Naume V. Tavengwa, and Jean H. Humphrey, Zvitambo Institute for Maternal and Child Health Research, Harare, Zimbabwe, E-mails: k.mutasa@zvitambo.com, r.ntozini@zvitambo.com, lesmith6@buffalo. edu, n.tavengwa@zvitambo.com, and jhumphr2@jhu.edu.

This is an open-access article distributed under the terms of the Creative Commons Attribution (CC-BY) License, which permits unrestricted use, distribution, and reproduction in any medium, provided the original author and source are credited.

\section{REFERENCES}

1. UNICEF, World Health Organization, World Bank Group, 2017. Levels and Trends in Child Malnutrition in UNICEF/WHO/World Bank Group Joint Child Malnutrition Estimates Key Findings of the 2016 Edition. Geneva, Switzerland: WHO.

2. de Onis M, Branca F, 2016. Childhood stunting: a global perspective. Matern Child Nutr 12 (Suppl 1): 12-26.

3. Bhutta ZA, Das JK, Rizvi A, Gaffey MF, Walker N, Horton S, Webb $P$, Lartey A, Black RE, 2013. Evidence-based interventions for improvement of maternal and child nutrition: what can be done and at what cost? Lancet 382: 452-477.
4. Budge S, Parker AH, Hutchings PT, Garbutt C, 2019. Environmental enteric dysfunction and child stunting. Nutr Rev 77: 240-253.

5. Checkley W, Buckley G, Gilman RH, Assis AM, Guerrant RL, Morris SS, MølbakK, Valentiner-Branth P, Lanata CF, Black RE, 2008. Multi-country analysis of the effects of diarrhoea on childhood stunting. Int J Epidemiol 37: 816-830.

6. Kosek MN, 2017. Causal pathways from enteropathogens to environmental enteropathy: findings from the MAL-ED birth cohort study. EBioMedicine 18: 109-117.

7. Rogawski ET et al., 2018. Use of quantitative molecular diagnostic methods to investigate the effect of enteropathogen infections on linear growth in children in low-resource settings: longitudinal analysis of results from the MAL-ED cohort study. Lancet Glob Health 6: e1319-e1328.

8. Humphrey $\mathrm{JH}, 2009$. Child undernutrition, tropical enteropathy, toilets, and handwashing. Lancet 374: 1032-1035.

9. Cumming $\mathrm{O}$ et al., 2019. The implications of three major new trials for the effect of water, sanitation and hygiene on childhood diarrhea and stunting: a consensus statement. BMC Med 17: 173.

10. Pickering AJ et al., 2019. The WASH benefits and SHINE trials: interpretation of WASH intervention effects on linear growth and diarrhoea. Lancet Glob Health 7: e1139-e1146.

11. Prendergast AJ et al., 2019. Putting the "A" into WaSH: a call for integrated management of water, animals, sanitation, and hygiene. Lancet Planet Health 3: e336-e337.

12. FAO Animal Production and Health Division, 2014. Livestock and Animal Production. Available at: http://www.fao.org/ag/againfo/ themes/en/animal production.html. Accessed March 27, 2017.

13. Guèye EHF, 1998. Village egg and fowl meat production in Africa. World's Poult Sci J 54: 73-86.

14. Das S, Chowdhury S, Khatun M, Nishibori M, Isobe N, Yoshimura $Y, 2008$. Poultry production profile and expected future projection in Bangladesh. World's Poult Sci J 64: 99-118.

15. Dolberg F, 2007. Poultry production for livelihood improvement and poverty alleviation. In: Thieme O., Pilling D., eds. Poultry in the 21st Century: Avian Influenza and Beyond. Proceedings of the International Poultry Conference, Bangkok, Thailand, November 5-7, 2007.

16. Kryger KN, Thomsen K, Whyte M, Dissing M, 2008. Smallholder Poultry Production: Livelihoods, Food Security and Sociocultural Significance. Rome, Italy: Network for Smallholder Poultry Development, FAO.

17. Herrero M, Grace D, Njuki J, Johnson N, Enahoro D, Silvestri S, Rufino MC, 2013. The roles of livestock in developing countries. Animal 7 (Suppl 1): 3-18.

18. Neumann C, Harris DM, Rogers LM, 2002. Contribution of animal source foods in improving diet quality and function in children in the developing world. Nutr Res 22: 193-220.

19. Trinh P, Zaneveld JR, Safranek S, Rabinowitz PM, 2018. One health relationships between human, animal, and environmental microbiomes: a mini-review. Front Public Health 6: 235.

20. Chuma IS, Nonga HE, Mdegela RH, Kazwala RR, 2016. Epidemiology and RAPD-PCR typing of thermophilic campylobacters from children under five years and chickens in Morogoro municipality, Tanzania. BMC Infect Dis 16: 692.

21. Zambrano LD, Levy K, Menezes NP, Freeman MC, 2014. Human diarrhea infections associated with domestic animal husbandry: a systematic review and meta-analysis. Trans $R$ Soc Trop Med Hyg 108: 313-325.

22. Penakalapati G, Swarthout J, Delahoy MJ, McAliley L, Wodnik B, Levy K, Freeman MC, 2017. Exposure to animal feces and human health: a systematic review and proposed research priorities. Environ Sci Technol 51: 11537-11552.

23. Berendes DM, Yang PJ, Lai A, Hu D, Brown J, 2018. Estimation of global recoverable human and animal faecal biomass. Nat Sustain 1: 679-685.

24. Ercumen A et al., 2017. Animal feces contribute to domestic fecal contamination: evidence from $E$. coli measured in water, hands, food, flies, and soil in Bangladesh. Environ Sci Technol 51: 8725-8734.

25. Baker KK, Senesac R, Sewell D, Sen Gupta A, Cumming O, Mumma J, 2018. Fecal fingerprints of enteric pathogen contamination in public environments of Kisumu, Kenya, associated with human sanitation conditions and domestic animals. Environ Sci Technol 52: 10263-10274. 
26. Barnes AN, Anderson JD, Mumma J, Mahmud ZH, Cumming O, 2018. The association between domestic animal presence and ownership and household drinking water contamination among peri-urban communities of Kisumu, Kenya. PLoS One 13: e0197587.

27. Harris AR, Pickering AJ, Harris M, Doza S, Islam MS, Unicomb L, Luby S, Davis J, Boehm AB, 2016. Ruminants contribute fecal contamination to the urban household environment in Dhaka, Bangladesh. Environ Sci Technol 50: 4642-4649.

28. Boehm AB, Wang D, Ercumen A, Shea M, Harris AR, Shanks OC, Kelty C, Ahmed A, Mahmud ZH, Arnold BF, 2016. Occurrence of host-associated fecal markers on child hands, household soil, and drinking water in rural Bangladeshi households. Environ Sci Technol Lett 3: 393-398.

29. Schriewer A, Odagiri M, Wuertz S, Misra PR, Panigrahi P, Clasen $T$, Jenkins MW, 2015. Human and animal fecal contamination of community water sources, stored drinking water and hands in rural India measured with validated microbial source tracking assays. Am J Trop Med Hyg 93: 509-516.

30. Prüss-Ustün A et al., 2014. Burden of disease from inadequate water, sanitation and hygiene in low- and middle-income settings: a retrospective analysis of data from 145 countries. Trop Med Int Health 19: 894-905.

31. Julian TR, 2016. Environmental transmission of diarrheal pathogens in low and middle income countries. Environ Sci Process Impacts 18: 944-955.

32. Sclar GD, Penakalapati G, Amato HK, Garn JV, Alexander K, Freeman MC, Boisson S, Medlicott KO, Clasen T, 2016. Assessing the impact of sanitation on indicators of fecal exposure along principal transmission pathways: a systematic review. Int J Hyg Environ Health 219: 709-723.

33. Moya J, Bearer CF, Etzel RA, 2004. Children's behavior and physiology and how it affects exposure to environmental contaminants. Pediatrics 113: 996-1006.

34. Kwong LH, Ercumen A, Pickering AJ, Unicomb L, Davis J, Luby SP, 2016. Hand- and object-mouthing of rural Bangladeshi children 3-18 months old. Int J Environ Res Public Health 13: 563.

35. Ngure FM et al., 2013. Formative research on hygiene behaviors and geophagy among infants and young children and implications of exposure to fecal bacteria. Am J Trop Med Hyg 89: 709-716.

36. Morita T et al., 2017. Mouthing of soil contaminated objects is associated with environmental enteropathy in young children. Trop Med Int Health 22: 670-678.

37. George CM et al., 2015. Geophagy is associated with environmental enteropathy and stunting in children in rural Bangladesh. Am J Trop Med Hyg 92: 1117-1124.

38. Perin $\mathrm{J}$ et al., 2016. Geophagy is associated with growth faltering in children in rural Bangladesh. J Pediatr 178: 34-39.e1.

39. Headey D, Nguyen P, Kim S, Rawat R, Ruel M, Menon P, 2017. Is exposure to animal feces harmful to child nutrition and health outcomes? A multicountry observational analysis. Am J Trop Med Hyg 96: 961-969.

40. Headey D, Hirvonen K, 2016. Is exposure to poultry harmful to child nutrition? An observational analysis for rural Ethiopia. PLoS One 11: e0160590.

41. Ordiz MI, Shaikh N, Trehan I, Maleta K, Stauber J, Shulman R, Devaraj S, Tarr PI, Manary MJ, 2016. Environmental enteric dysfunction is associated with poor linear growth and can be identified by host fecal mRNAs. J Pediatr Gastroenterol Nutr 63: 453-459.

42. Callaway TR, Anderson RC, Edrington TS, Genovese KJ, Harvey RB, Poole TL, Nisbet DJ, 2004. Recent pre-harvest supplementation strategies to reduce carriage and shedding of zoonotic enteric bacterial pathogens in food animals. Anim Health Res Rev 5: 35-47.
43. Chen S, Sanderson MW, White BJ, Amrine DE, Lanzas C, 2013. Temporal-spatial heterogeneity in animal-environment contact: implications for the exposure and transmission of pathogens. Sci Rep 3: 3112

44. Montealegre MC, Roy S, Böni F, Hossain MI, Navab-Daneshmand T, Caduff L, Faruque ASG, Islam MA, Julian TR, 2018. Risk factors for detection, survival, and growth of antibiotic-resistant and pathogenic Escherichia coli in household soils in rural Bangladesh. Appl Environ Microbiol 84: e01978-18.

45. Montealegre MC, Talavera Rodríguez A, Roy S, Hossain MI, Islam MA, Lanza VF, Julian TR, 2020. High genomic diversity and heterogenous origins of pathogenic and antibiotic-resistant Escherichia coli in household settings represent a challenge to reducing transmission in low-income settings. mSphere 5: e00704-19.

46. Delahoy MJ, Wodnik B, McAliley L, Penakalapati G, Swarthout J, Freeman MC, Levy K, 2018. Pathogens transmitted in animal feces in low- and middle-income countries. Int J Hyg Environ Health 221: 661-676.

47. Jochum L, Stecher B, 2020. Label or concept-what is a pathobiont? Trends Microbiol 28: 789-792.

48. Vasco K, Graham JP, Trueba G, 2016. Detection of zoonotic enteropathogens in children and domestic animals in a semirural community in Ecuador. Appl Environ Microbiol 82: 4218-4224.

49. Brown J, Cumming O, 2020. Stool-based pathogen detection offers advantages as an outcome measure for water, sanitation, and hygiene trials. Am J Trop Med Hyg 102: 260-261.

50. Xavier RJ, 2020. Growth and the microbiome-integrating global health with basic science. N Engl J Med 383: 391-393.

51. Hernando-Amado S, Coque TM, Baquero F, Martínez JL, 2019. Defining and combating antibiotic resistance from one health and global health perspectives. Nat Microbiol 4: 1432-1442.

52. Matilla F, Velleman Y, Harrison W, Nevel M, 2018. Animal influence on water, sanitation and hygiene measures for zoonosis control at the household level: a systematic literature review. PLoS Negl Trop Dis 12: e0006619.

53. Harvey SA, Winch PJ, Leontsini E, Torres Gayoso C, López Romero S, Gilman RH, Oberhelman RA, 2003. Domestic poultry-raising practices in a Peruvian shantytown: implications for control of Campylobacter jejuni-associated diarrhea. Acta Trop 86: 41-54.

54. Mbuya MN et al., 2015. Design of an intervention to minimize ingestion of fecal microbes by young children in rural Zimbabwe. Clin Infect Dis 61 (Suppl 7): S703-S709.

55. Bardosh KL, Hussein JW, Sadik EA, Hassen JY, Ketema M, Ibrahim AM, McKune SL, Havelaar AH, 2020. Chicken eggs, childhood stunting and environmental hygiene: an ethnographic study from the Campylobacter genomics and environmental enteric dysfunction (CAGED) project in Ethiopia. One Health Outlook 2: 1-15.

56. Gelli A, Becquey E, Ganaba R, Headey D, Hidrobo M, Huybregts L, Verhoef H, Kenfack R, Zongouri S, Guedenet H, 2017. Improving diets and nutrition through an integrated poultry value chain and nutrition intervention (SELEVER) in Burkina Faso: study protocol for a randomized trial. Trials 18: 412.

57. Perry B, Randolph T, McDermott J, Sones K, Thornton P, 2002. Investing in Animal Health Research to Alleviate Poverty. Nairobi, Kenya: International Livestock Research Institute (ILRI).

58. Eaton JC, Rothpletz-Puglia P, Dreker MR, lannotti L, Lutter C, Kaganda J, Rayco-Solon P, 2019. Effectiveness of provision of animal-source foods for supporting optimal growth and development in children 6 to 59 months of age. Cochrane Database Syst Rev 2: Cd012818.

59. Headey D, Hirvonen K, Hoddinott J, 2018. Animal sourced foods and child stunting. Am J Agric Econ 100: 1302-1319. 